\title{
Melanotic progonoma of the skull
}

\author{
D. I. ANAGNOSTOPOULOS AND G. J. H. EVERARD \\ From the Regional Centre for Neurology and Neurosurgery, and the Department of Radiology, \\ Oldchurch Hospital, Romford, Essex
}

SUMMARY A case of progonoma of the skull
theories as to the histogenesis of this rare tumou
The progonoma is a rare tumour of bone occurring almost exclusively in the upper or lower jaw of infants during the first year of life. The tumour has been called by a variety of names-melanotic adamantinoma, melanotic epithelial odontoma, odontogenic hamartoma, melano-ameloblastoma, retinal anlage tumour, pigmental epulis, melanotic progonoma-indicating the differing views as to the origin of the tumour. Exceptionally, the tumour may occur

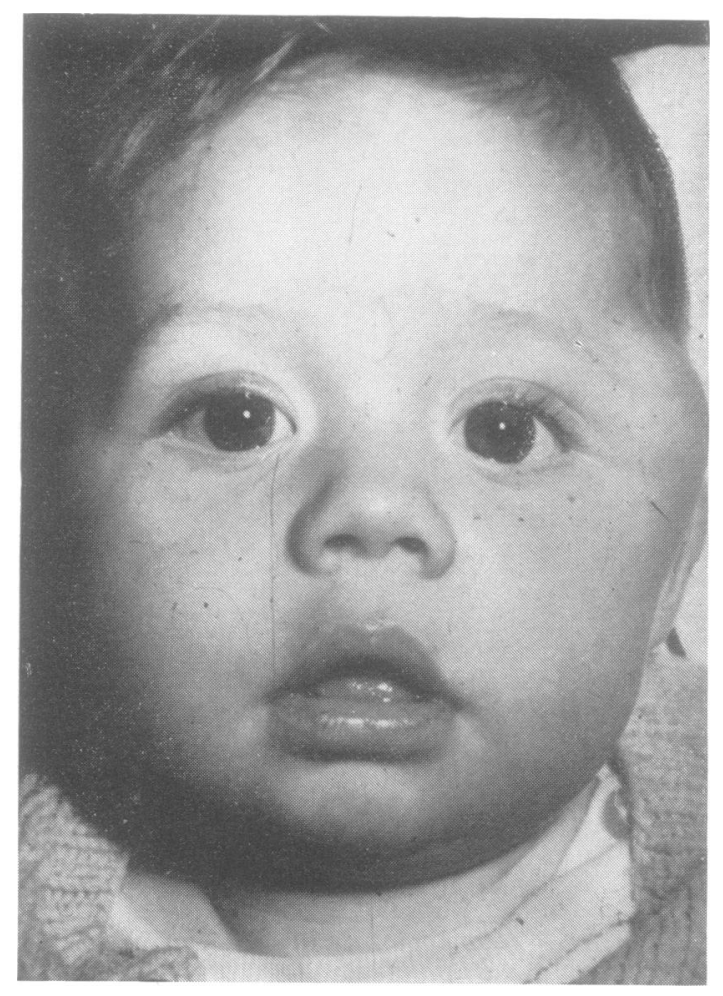

FIG. 1. Clinical photograph showing the site of the tumour. in the skull; three such cases have been reported, and this paper records a fourth.

\section{CASE REPORT}

D.C.F., a 7 month old boy, was referred on 17 August 1970 with a painless swelling at the lateral $\dot{\omega}$ border of the left orbit (Fig. 1). The swelling had appeared two months earlier and had grown steadil in size. It did not appear to be causing any discomfoit $\infty$ to the child and it was not tender to touch. The chipd 5 appeared to be quite well in every other way. \& examination there was a bony-hard, smooth, domeshaped swelling $4 \mathrm{~cm}$ in diameter in the left frontotemporal region. It was firmly attached to the skư⿰亻⿱丶⿻工二口. The skin moved freely over it. There were no abnofmalities in the central nervous system and genera examination was negative.

INVESTIGATIONS Blood count was normal. Brain scan showed a large area of high uptake in the left $\overline{0}$ frontotemporal region. Radiography of the chest, $\stackrel{\circ}{\circ}$ skeletal survey, and intravenous pyelogram were $\varrho$ normal.

Radiological findings Skull films showed a bony mass in the left frontotemporal area (Fig. 2), corresponding with the soft tissue swelling and extending into the sphenoidal wing. The mass expandedo medially to form a sharply defined, rounded shadow of even density. More diffuse bony shadowing extended outwards into the soft tissues, a tangential 0 film also suggesting the presence of poorly formed, radiating spicules. This feature gave rise to early suspicion of osteogenic sarcoma. A search for $D$ secondary deposits or, alternatively, for an osteoblastic primary tumour elsewhere was negative.

Left carotid angiography showed that the main blood supply to the inner mass derived from the $N$

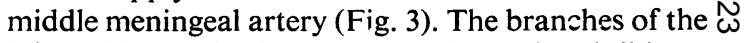
left middle cerebral artery were elevated and did not $\bar{\sigma}$ quite reach to the inner surface of the skull in thato 


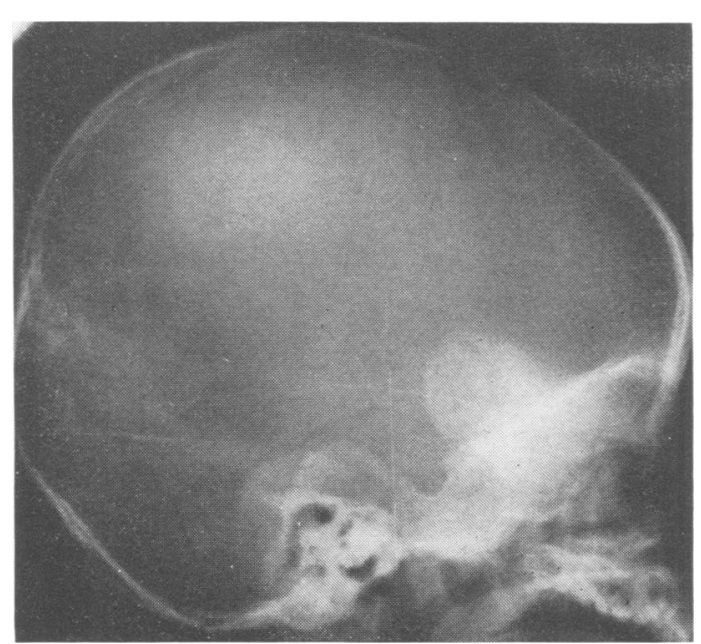

FIG. 2. Radiograph of the skull showing the bony mass.

area. This corresponded with the finding at operation of a localized and extradural mass of tumour tissue. Lateral arteriograms showed a late 'tumour blush'. As this also extended downwards to below the level of the floor of the anterior fossa, it was probably mainly due to the circulation in the mass in the soft tissues. The blood supply to the latter appeared to derive from an anastomosis fed partly by the enlarged ophthalmic artery and from branches of

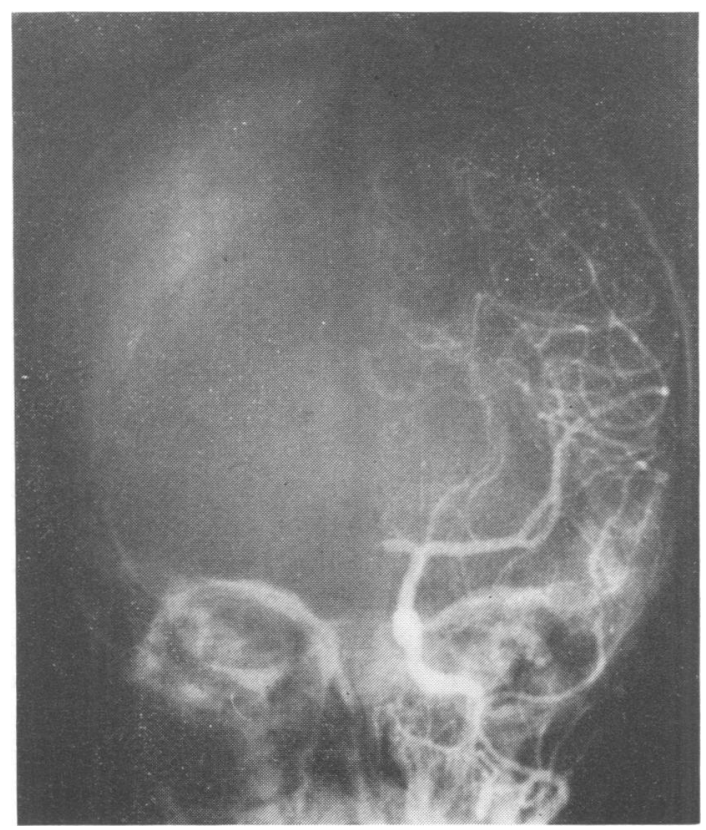

FIG. 3. AP carotid angiogram the external carotid. No large internal drainage veins were found but the nearby jugular vein filled very early during the arterial phase, before the deep veins.

The tumour was now thought to be a meningioma presenting exceptionally early in life. In their review of intracranial neoplastic diseases of childhood, Bodian and Lawson (1953) suggest that meningiomas often arise very early in life, escaping recognition until very large. This is attributed to the rarity of obstruction of flow of cerebrospinal fluid owing to their frequently favourable site. They quote only five cases of such meningiomas in children ranging in age from $1 \frac{1}{4}$ to 4 years, the distribution being frontal (three), temporal, and parietal. Intracerebral calcification and bone erosion are quoted as features of meningiomas in this early age group.

Despite the age of the infant, there were thus many points of radiological similarity between the present tumour and a meningioma. Besides the aetiological interest implicit in the situation and vascular supply of this progonoma, the differential diagnosis of meningioma during infancy remained relevant to the purely radiological findings.

On 24 August 1970 a biopsy of the tumour was carried out. The tumour was bony-hard and vascular. Histological examination showed trabeculae of normal looking cancellous bone. The spaces between the trabeculae were filled by fibrous connective tissue which in some parts took on a rather dense and hyperchromatic appearance and was associated with the production of melanin. The most probable diagnosis was thought to be a hyperostosis due to an underlying and invading fibroblastic meningioma.

Operation (1 September 1970, Mr. Bernard Fairburn). A large left frontotemporal scalp flap was reflected. A bone flap, taken to the margins of the tumour, was then turned down. It could now be seen that the externally visible tumour was part of a large globular mass, approximately $5 \mathrm{~cm}$ in diameter projecting intracranially at the junction of the anterior and middle cranial fossae. It was entirely extradural and the temporal and frontal lobes of the brain were displaced medially by the tumour. The greater part of the mass consisted of vascular bone which had to be chiselled away. However, the deeper part of the tumour which was in relation to the dura mater was velvety red in colour and soft in consistency. It stripped fairly easily from the dura mater which was clearly not invaded. The soft part of the tumour was removed by rongeur. The main mass of vascular bone was removed. Bony thickening, however, extended widely into the sphenoidal wing, the lateral margin of the orbit, and the floor of the temporal fossa. All vascular bone was removed but no attempt was made to remove all thickened but otherwise normal looking bone. A skull defect some $6 \mathrm{~cm}$ in diameter was now left and this was covered by an acrylic prosthesis. 


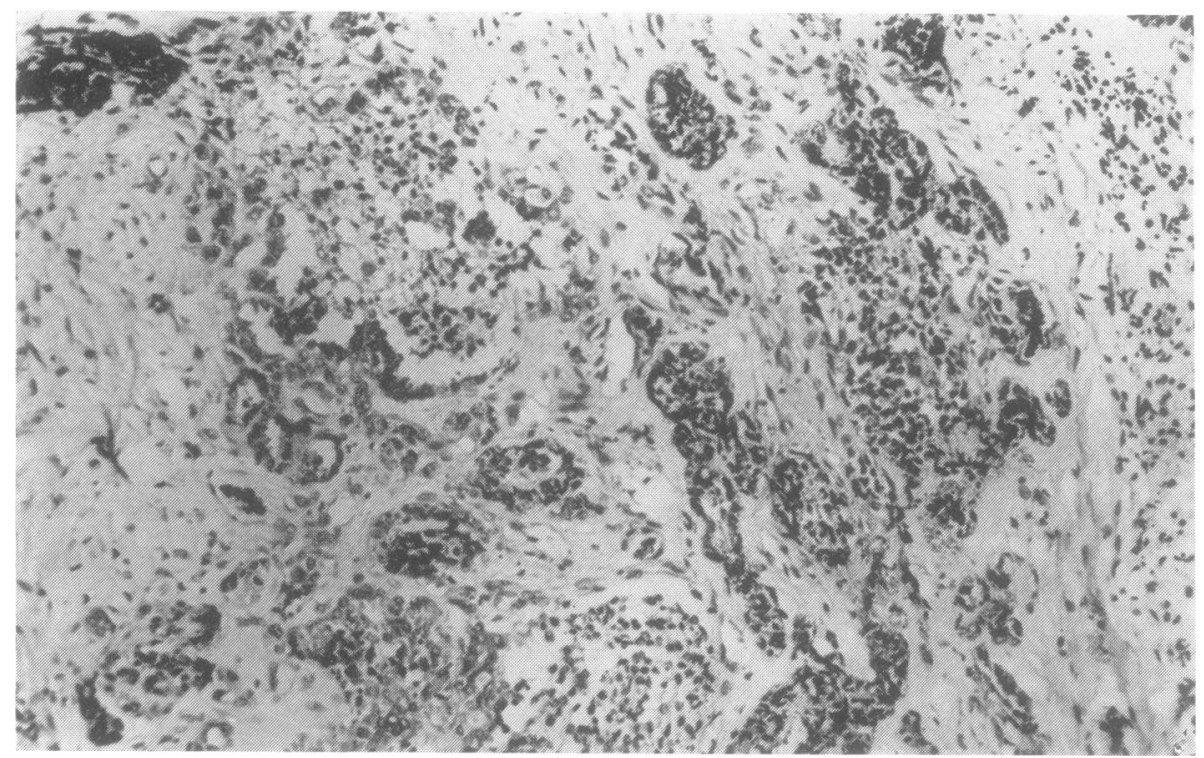

FIG. 4. Histological appearance of the tumour. Haematoxylin and eosin, $\times 135$.

The child made an uneventful recovery and was discharged home well on 11 September 1970. He has remained well with no evidence of recurrence since then, a period of six months.

Pathology (Professor H. Urich) The tumour consisted of islands of epithelial cells scattered in a connective tissue stroma (Fig. 4). The epithelial cells formed either solid clumps, or a cuboidal lining to irregular tubules, elongated clefts or small cysts. Most of these cells contained granules of a dark brown pigment which gave the staining reactions of melanin. In some cells the pigment was sparse, in others it was abundant to the point of obliteration of cellular detail. Some of the epithelial cells, particularly those forming solid clusters, were unpigmented and could be seen to consist of a small, densely staining nucleus surrounded by clear, pale, cytoplasm.

The stroma consisted of strands of spindle cells in a fibrillary matrix, forming interlacing bundles, with some tendency to whorl formation, but no palisading. The cellularity of the stroma varied in different areas from low to moderate. In some parts of the tumour stromal elements predominated to the exclusion of epithelial islands. No mitoses could be seen either in the epithelial or in the stromal cells.

The tumour invaded the surrounding bone with extensive destruction of bony trabeculae as well as abundant osteoid and new bone formation. The appearances were those of a melanotic progonoma.

\section{DISCUSSION}

The first report of this tumour was made by
Halpert and Palzer (1947) who described a tumour of the maxilla which they believed to be $\overrightarrow{\mathrm{\Phi}}$ 음 composed of misplaced retinal elements which $\frac{\vec{Q}}{2}-$ they described as a retinal anlage tumour. Someo 7 30 additional cases have since been described Stowens (1957) reviewed the literature and waș ฏ able to collect 24 cases including three of his own. He was the first person to call the tumour a melanotic progonoma. Nearly all the cases described have been in the jaws of infants under the age of 1 year. Local excision has been used in all cases and although an occasional recurrence has been observed, necessitating further operation, all these patients appear ultimately to have been cured of their disease. The tumour, therefore, although unencapsulated and locally invasive, appears to be essentially benign in character and the prognosis uniformly good.

There have been only three references to progonomas occurring in the skull. Clarke and Parsons (1951) described a case involving the skull in the region of the anterior fontanelle in a 9 month old boy. A similar lesion in the same situation was described by Kuhn, Cabonne, and Garneau (1954) in a 3 month old girl. Ashley (1964) reported a similar bony tumour of the skull just posterior to the right mastoid process in a 2 month old boy. All these children appear to have been cured by local excision of their tumours.

Our case is therefore the fourth reported 
example of a skull progonoma. A few points of special interest emerge in this case. The very dense new bone formation does not seem to have occurred in other cases, nor did any of them project so far into the cranial cavity. The meningeal blood supply to the tumour demonstrated at angiography has not previously been noted and may perhaps lend support to the theory of a possible meningeal origin for these tumours.

Most progonomas have been described as being of slaty or black colour. In our case, the soft part of the tumour was deep red in colour and the presence of melanin was established only at microscopy. It would appear that the melanin content of these tumours may vary considerably.

The chief interest of these tumours lies in the debate which has arisen in regard to their histogenesis, a debate which is reflected in the many eponyms which the tumour has acquired. Halpert and Patzer (1947), who first described the tumour, were struck by its histological resemblance to the primitive retina and suggested that the tumours arose from the retinal cells misplaced during the complicated embryological development of the face. Stowens (1957) rejected the theory of a retinal origin for these tumours on a number of grounds. He pointed out that the retina is well organized in the $7 \mathrm{~mm}$ embryo while the anlagen of the upper and lower jaws are just beginning to form. He thought that the 'pinching off' of the more developed tissue by the less developed was difficult to envisage. No counterparts of the sclera or choroid had ever been found in the tumour, and in no case had an associated deficiency of the eye been described. He suggested that the tumours arose from pig- mented sensory neuroectodermal structures, possibly the vomeronasal organs of Jacobson. Willis (1962) believed that the tumours arose from paradental epithelial residues. None of these theories adequately explains the occurrence of such tumours in the skull. Ashley (1964) described a tumour of the skull behind the right mastoid process and suggested that the tumour might be a leptomeningeal hamartoma.

It will be apparent from this brief discussion that no single universally accepted theory has yet been advanced to explain the nature of these rare tumours.

We are grateful to Mr. Bernard Fairburn for permission to publish his case and for help with the manuscript, to Professor $\mathrm{H}$. Urich for permission to publish his morbid anatomical findings and for kindly supplying the photomicrograph and to Dr. Ian Larkin for examining the surgical specimen first and suggesting the histological diagnosis.

\section{REFERENCES}

Ashley, D. J. B. (1964). Melanotic 'adamantinoma' of the skull. Journal of Pathology and Bacteriology, 87, 179-181.

Bodian, M., and Lawson, D. (1953). The intracranial neoplastic diseases of childhood. British Journal of Surgery, 40, 368-392.

Clarke, B. E., and Parsons, H. (1951). An embryological tumor of retinal anlage involving the skull. Cancer, 78-85.

Halpert, B., and Patzer, R. (1947). Maxillary tumor of retinal anlage. Surgery, 22, 837-841.

Kuhn, R., Cabanne, F., and Garneau, R. (1954). Le rétinoblastome pigmentaire hétérotopique. Rapport d'un cas et étude générale. Semaine des Hopitaux, Archive d'Anatomie Pathologique, 30, A178-A185.

Stowens, D. (1957). A pigmented tumour of infancy: the melanotic progonoma. Journal of Pathology and Bacteriology, 73, 41-51.

Willis, R. A. (1962). The Borderland of Embryology and Pathology, 2nd edn, p. 273. Butterworths: London. 